\title{
Chorda Tympani Transection and Selective Desalivation Differentially Disrupt Two-Lever Salt Discrimination Performance in Rats
}

\author{
Steven J. St. John, Stacy Markison, Nick A. Guagliardo, Timothy D. Hackenberg, and Alan C. Spector \\ University of Florida
}

\begin{abstract}
Water-restricted rats were trained to press 1 of 2 levers if a sampled stimulus was $\mathrm{NaCl}$ and the other lever if the stimulus was $\mathrm{KCl}(0.05,0.1$, or $0.2 \mathrm{M})$. Responses were reinforced with water. After training, the average rate of correct responses was $90 \%$. Performance was unchanged following sham surgery. Chorda tympani (CT) transection reduced average discrimination performance to $67.7 \%$ correct, and extirpation of the sublingual and submaxillary salivary glands reduced average performance to $80 \%$ correct. Although selective desalivation moderately reduced discriminability, a disrupted salivary environment does not explain the effects of CT transection. More likely, the discrimination deficit in CT-transected rats reflects a loss of critical taste input conveyed by the $\mathrm{CT}$ about salts.
\end{abstract}

A variety of behavioral evidence indicates that the chorda tympani nerve (CT) is important in coding salt taste in the rat (Breslin, Spector, \& Grill, 1993, 1995; Markison, St. John, \& Spector, 1995; O'Keefe, Schumm, \& Smith, 1994; Slotnick, Sheelar, \& Rentmeister-Bryant, 1991; Sollars \& Bernstein, 1992, 1994; Sollars, Sollars, \& Bernstein, 1991; Spector \& Grill, 1992, 1994; Spector, Schwartz, \& Grill, 1990; St. John, Markison, \& Spector, 1995; Yamamoto, Shimura, Sako, Yasoshima, \& Sakai, 1994). For example, $\mathrm{CT}$ transection elevates the detection threshold for $\mathrm{NaCl}$ as much as 2 orders of magnitude (Slotnick et al., 1991; Spector et al., 1990); disrupts the specificity of depletioninduced sodium appetite (Breslin et al., 1993, 1995; Markison et al., 1995); can impair the expression of a presurgically conditioned taste aversion to $\mathrm{NaCl}$ (Yamamoto et al., 1994); and in Fischer 344 rats reverses the uncharacteristic aversion to low concentrations of $\mathrm{NaCl}$ to a preference (Sollars et al., 1991; Sollars \& Bernstein, 1994). In contrast, $\mathrm{NaCl}$ sensibility appears to be unaffected by glossopharyngeal nerve transection (Cauthon, Garcea, \& Spector, 1994; Markison et al. 1995; Sollars \& Bernstein, 1994; Spector \& Grill, 1992; Yamamoto et al., 1994), which denervates approximately 4 times as many taste buds as does CT transection (see Miller, 1977).

Spector and Grill (1992) demonstrated that CT transection

Steven J. St. John, Stacy Markison, Nick A. Guagliardo, Timothy D. Hackenberg, and Alan C. Spector, Department of Psychology, University of Florida.

This research was supported, in part, by Public Health Service grants (R01-DC-01628 and R29-MH-50244), a National Science Foundation Graduate Fellowship, and a Research Career Development Award from the National Institute on Deafness and Other Communication Disorders (K04-DC-00104). Portions of this work were presented in 1996 at the 18th Annual Meeting of the Association for Chemoreception Sciences, Sarasota, Florida (St. John, Markison, Guagliardo, Hackenberg, \& Spector, 1996).

Correspondence concerning this article should be addressed to Alan C. Spector, Department of Psychology, University of Florida, Gainesville, Florida 32611-2250. Electronic mail may be sent to spector@psych.ufl.edu. substantially impaired performance on a presurgically learned $\mathrm{NaCl}$-versus- $\mathrm{KCl}$ discrimination task (see also St. John et al., 1995). Moreover, transection of the glossopharyngeal nerve did not affect discrimination performance, and CT transection did not disrupt a sucrose-versus-quinine taste discrimination. One interpretation of these results is that the $\mathrm{CT}$ is critical in the perception of the quality or intensity of one or both salts. Because the CT also innervates the sublingual and submaxillary salivary glands, however, the possibility could not be ruled out that the effects on taste discrimination were caused by a disruption in the salivary environment rather than by the denervation of anterior tongue taste buds.

Sublingual and submaxillary salivary gland extirpation has been shown to affect rats' performance in behavioral taste tests involving salts (Brosvic \& Hoey, 1990; Catalanotto \& Sweeney, 1973; Cauthon, Garcea, \& Spector, 1994; Markison et al., 1995; Thrasher \& Fregly, 1980). For example, Brosvic and Hoey (1990) found that extirpation of the sublingual and submaxillary salivary glands reduced preference for $0.15 \mathrm{M} \mathrm{NaCl}$ and increased preference for $0.15 \mathrm{M} \mathrm{KCl}$, relative to controls. Performance of the same rats, however, was unaffected in a conditional discrimination task in which they were trained to respond differentially to $0.068 \mathrm{M} \mathrm{NaCl}$ and other taste stimuli (including $0.068 \mathrm{M}$ $\mathrm{KCl}$ ). In the present study, we examined the possible effects of selective desalivation on $\mathrm{NaCl}$ and $\mathrm{KCl}$ discrimination across the same concentration range $(0.05-0.2 \mathrm{M})$ used in previous studies of CT transection (Spector \& Grill, 1992; St. John et al., 1995).

In those salt-discrimination studies, rats were trained to lick in the presence of one salt during a 5-s trial and suppress licking in the presence of the other. Discriminability was evidenced by a high number of licks to one salt and a low number of licks to the other. However, extirpation of the sublingual and submaxillary salivary glands has been shown to disturb licking under some circumstances (Spector, Redman, \& Garcea, 1996; St. John, Garcea, \& Spector, 1994; Wong \& Kraintz, 1977). These nonspecific effects could potentially confound any sensory effects of removing the 
salivary glands. It was necessary, therefore, to develop a discrimination paradigm that did not rely on licking as the dependent response. We chose to modify the 2-lever discrimination paradigm of Morrison (1967). In brief, waterrestricted rats were trained to press one lever if the sampled stimulus was $\mathrm{NaCl}$ and the other if it was $\mathrm{KCl}$. Correct presses were reinforced with distilled water; incorrect presses were punished with a time-out period during which fluid was unavailable. To directly compare the effects of selective desalivation with those of CT transection, we transected the CT in an additional group of rats and tested them in this paradigm.

\section{Method}

\section{Subjects}

Sixteen naive, adult, male, Sprague-Dawley rats (Charles River, Wilmington, MA) were housed individually in hanging, wire-mesh cages in a room where lighting, humidity, and temperature were automatically controlled. The rats weighed $290-319 \mathrm{~g}$ at the start of the experiment. Purina Rat Chow 5001 (Ralston-Purina, St. Louis, $\mathrm{MO}$ ) was available at all times on the home cage; distilled water was available except approximately $24 \mathrm{hr}$ prior to behavioral sessions. In general, training and testing sessions took place on Monday through Friday. Home-cage-distilled water bottles were replaced after the session on Friday and removed $20-26 \mathrm{hr}$ prior to the session on Monday. All manipulations were performed during the lights-on phase of the 12-hr light-dark cycle (lights on 6am-6pm).

\section{Apparatus}

The design of the apparatus was modified from the gustometer of Spector, Andrews-Labenski, and Letterio (1990). The primary advantage of this computerized apparatus was that it allowed up to 12 different taste stimuli to be delivered randomly in brief-access trials while licking was measured. A computer-controlled motorized drive regulated the positioning of 2 drinking spouts (the reinforcement spout and the sample spout), such that the reinforcement spout, the sample spout, or neither spout could be in position in front of the stimulus-access slit at any given time. Fluid was delivered at approximately $5 \mu \mathrm{l}$ per lick. Furthermore, between taste trials, the sample spout was positioned over a drainage funnel, rinsed with distilled water, and dried with 2 bursts of pressurized air. Inside the operant chamber, 2 identical levers (BRS/LVE, Laurel, MD) were positioned $80 \mathrm{~mm}$ to the left and the right of the stimulus-access slit and $40 \mathrm{~mm}$ above the grid floor of the chamber. Approximately $50 \mathrm{~mm}$ above each lever was a small cue light covered with clear glass that was operated by the computer.

\section{Trial Structure}

The trial structure is illustrated schematically in the flowchart of Figure 1. Various phases of the trial were cued by the availability of the sample or reinforcement spout and by illuminating the house lights or cue lights (Table 1). At the beginning of a session, the sample spout was positioned in front of the stimulus-access slit. When the rat licked the drinking spout twice within $250 \mathrm{~ms}$, the sampling phase of the trial began. The sample stimulus was $\mathrm{NaCl}$ $(0.05,0.1$, or $0.2 \mathrm{M}), \mathrm{KCl}(0.05,0.1$, or $0.2 \mathrm{M})$, or distilled water, depending on the trial and the phase of the experiment (Table 2). The sampling phase terminated after the rat made 10 licks or $3 \mathrm{~s}$

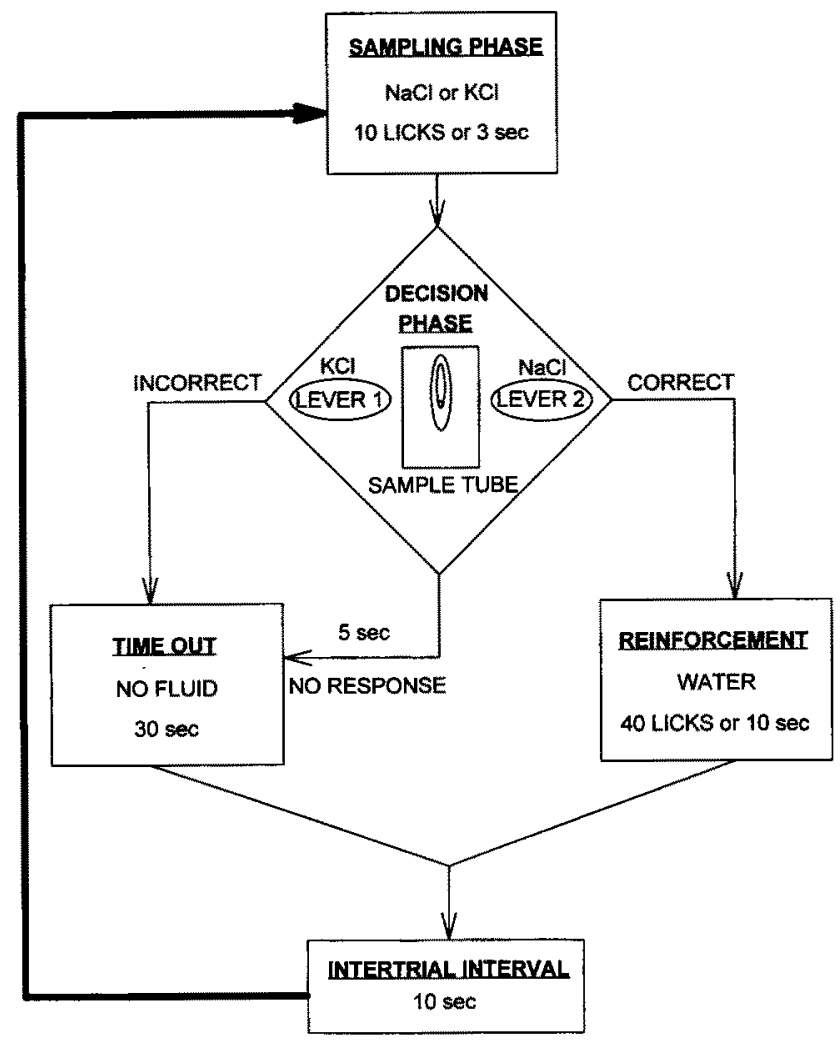

Figure 1. Flow chart schematic of the trial structure. A trial was initiated following 2 licks on the sample spout. After 10 licks or $3 \mathrm{~s}$, during which the rat receives either $\mathrm{NaCl}$ or $\mathrm{KCl}$, the sample spout was removed. A lever press was then required within $5 \mathrm{~s}$. A correct press (e.g., the right-hand lever when the sampled stimulus was $\mathrm{NaCl}$ ) produced a reinforcement period (40 licks or $10 \mathrm{~s}$ of distilled water). An incorrect press, or $5 \mathrm{~s}$ without a press, produced a 30-s time-out. The trial ended in either event with a $10 \mathrm{~s}$ intertrial interval, during which the sample spout was cleaned with water. The next trial began when the rat again licked the sample spout.

had elapsed following the onset of stimulus delivery (whichever came first). Because the maximal licking rate for a rat is roughly 6 licks/s, the sampling phase almost always terminated when the rat made its 10 th lick.

Immediately after the sample spout rotated out of position, the decision phase of the trial began. For a given rat, the left-right position of the $\mathrm{NaCl}$ - and $\mathrm{KCl}$-appropriate levers remained constant throughout the experiment (but were counterbalanced across subjects). Following a correct response, the reinforcement phase began, consisting of 40 licks from or $10-\mathrm{s}$ access to the distilled water spout. Following an incorrect response or the absence of a response during a 5-s limited-hold period, a 30-s time-out period

Table 1

Description of Phases During the Trial

\begin{tabular}{llcc}
\hline \multicolumn{1}{c}{ Phase } & \multicolumn{1}{c}{ Spout availability } & House lights & Cue lights \\
\hline Sampling phase & Sample spout & On & Off \\
Decision phase & None & Off & On \\
Reinforcement & Reinforcement spout & On & Off \\
Time out & None & Off & Off \\
Intertrial interval & None & Off & Off \\
\hline
\end{tabular}


Table 2

Description of Training Sessions

\begin{tabular}{clccll}
\hline Session & \multicolumn{1}{c}{ Phase } & Time-out $(\mathrm{s})$ & Limited hold $(\mathrm{s})^{\mathrm{a}}$ & Sample stimuli & \multicolumn{1}{c}{ Stimulus presentation schedule } \\
\hline $1-7^{\mathrm{b}}$ & Shaping & None $^{\mathrm{c}}$ & 180 & $0.1 \mathrm{M} \mathrm{NaCl}$ or $0.1 \mathrm{M} \mathrm{KCl}$ & Constant \\
$8-10$ & Alternation & 10 & 15 & $0.1 \mathrm{M} \mathrm{NaCl}$ and $0.1 \mathrm{M} \mathrm{KCl}$ & Alternated after $x$ correct responses $^{\mathrm{d}}$ \\
$11-12$ & Discrimination training & 10 & 10 & $0.1 \mathrm{M} \mathrm{NaCl}$ and $0.1 \mathrm{M} \mathrm{KCl}$ & Semirandom \\
$13-15$ & Discrimination training & 20 & 10 & $0.1 \mathrm{M} \mathrm{NaCl}$ and $0.1 \mathrm{M} \mathrm{KCl}$ & Semirandom \\
$16-17$ & Discrimination training & 20 & 5 & $0.05,0.1,0.2 \mathrm{M} \mathrm{NaCl}$ and $\mathrm{KCl}$ & Semirandom \\
$18-31$ & Discrimination training & 30 & 5 & $0.05,0.1,0.2 \mathrm{M} \mathrm{NaCl}$ and $\mathrm{KCl}$ & Semirandom \\
\hline
\end{tabular}

The length of the decision phase of the trial. ${ }^{b}$ Three rats received an additional shaping session. ${ }^{c}$ During the shaping phase, incorrect responses were ignored and failure to press any lever was not punished with a time-out. 'On Session $8, x=8$; Session 9, $x=6$; Session 10 , $x=4$. $\quad$ Stimuli were delivered in randomized blocks of 2 or 6 .

began. These contingencies took effect immediately after a lever press or at the end of the limited hold. The sample spout was then positioned over a drainage funnel for $10 \mathrm{~s}$ (intertrial interval) and cleaned as previously described.

After the intertrial interval terminated, the sample spout was repositioned in front of the stimulus-access slit, and the rat could initiate further trials in the manner detailed earlier. Session duration was fixed at $40 \mathrm{~min}$. The parameters listed here and in Figure 1 reflect the trial structure during the final stages of training and through pre- and postsurgical testing.

\section{Training Procedure}

The rats were trained to press one lever after sampling $\mathrm{NaCl}$ and the opposite lever after sampling $\mathrm{KCl}$. Taste stimuli were made daily from reagent-grade chemicals (Fisher Scientific, Orlando, FL) throughout the experiment. Over 31 training sessions, several parameters were adjusted gradually to match the procedure during pre- and postsurgical testing (Table 2).

Shaping. In addition to the parameters shown in Table 2, the shaping sessions were $45-\mathrm{min}$ in duration (rather than $40 \mathrm{~min}$ ), and the reinforcement phase terminated after 40 licks or $30 \mathrm{~s}$ (instead of $10 \mathrm{~s})$. During these initial training sessions, there was only 1 sample stimulus $(0.1 \mathrm{M} \mathrm{NaCl}$ or $0.1 \mathrm{M} \mathrm{KCl})$. The first salt presented and the corresponding correct lever (left or right) were counterbalanced across rats. An experimenter observed the sessions through a one-way mirror in the sound attenuation chamber enclosing the testing chamber and could control reinforcement delivery remotely. Initially, merely approaching the proper lever during the decision phase was reinforced. Over trials, the criterion for reinforcement gradually became more stringent, until lever pressing occurred (directly initiating the reinforcement phase). Rate of acquisition varied across rats. One rat that did not press the lever after 5 sessions was removed from the experiment. Three rats that did not press the appropriate lever until the fifth session were given an additional session on the following day (Saturday).

Over the next 2 sessions, the rats were trained to press the opposite lever after sampling the other salt. Most rats initially pressed the incorrect lever, but within the first session the rats began to press the lever appropriate for the second salt stimulus.

Alternation. For the remainder of the experiment, both salts were included in the stimulus array. During the alternation phase, the rat received several presentations of one salt on successive trials before receiving several trials with the other salt. For the first session, the salt the rat had received exclusively in the last shaping session was the sample stimulus on the first trial. Following 8 correct responses to the first salt (not necessarily 8 in a row), the sample stimulus alternated to the other salt. This stimulus alternation continued after 8 correct responses for the remainder of the session. The alternation criterion was reduced to 6 on the following session and then 4 on the last session of this phase (Table 2).
Discrimination training. During discrimination training, solutions were delivered in randomized blocks of 2 or 6 trials (see Table 2).

\section{Testing}

The presurgical assessment of salt discriminability occurred in 4 sessions that were identical to the final 14 sessions of discrimination training (Table 2). Following recovery from surgery, the rats received a 4 -session postsurgical assessment. On the next day, the rats were given a water control test. During this session, the 6 fluid reservoirs were filled with distilled water rather than salt solutions. Responses to 3 of the water stimuli were reinforced on the left lever; responses to the other 3 were reinforced on the right lever. The water control test was conducted to determine whether the rats could respond appropriately in the absence of chemical cues. Throughout the testing period (both pre- and postsurgically), as well as during the surgical recovery period, all rats were given a corn oil mash (5 parts Purina Rat Chow 5001:2 parts 100\% corn oil) in the home cage (see Catalanotto \& Sweeney, 1973; St. John et al., 1994). Because some rats were partially desalivated, this moist food diet was provided to ease swallowing during the testing periods when water was not available on the home cage. All rats continued to have access to pellets as well.

\section{Surgery}

All of the rats were assigned to one of 3 surgical groups, which were equated for overall percentage correct responses during the presurgical test. In addition, each group included at least 2 rats for which the left lever was the $\mathrm{NaCl}$-appropriate lever and at least 2 rats for which the right lever was the $\mathrm{NaCl}$-appropriate lever. All groups averaged an overall percentage correct of 90.0 during the presurgical test. The rats received a prophylactic dose of penicillin (DuoPen, 30,000 units) the day before surgery. The rats were anesthetized with a mixture of ketamine hydrochloride $(125 \mathrm{mg} / \mathrm{kg}$ body weight) and xylazine hydrochloride $(5 \mathrm{mg} / \mathrm{kg}$ body weight), which was injected into the musculature of the upper hindlimbs in 2 equal volumes on the left and right side. During surgery, the rats rested on isothermal heating pads.

Five rats received bilateral CT transection (the CTX group). The auditory meatus was retracted with 5 blunted and curved hypodermic needles. The tympanic membrane was punctured, the ossicles were removed, and the CT was avulsed with a \#7 microforceps. Five rats received extirpation of the sublingual and submaxillary salivary glands (the DSAL group). An incision was made in the ventral neck, and the fascia around the glands was dissected with 2 curved \#7 microforceps. The salivary duct was ligated with 4-0 silk suture and cut, and the glands were removed. The incision site was 
closed with 3-0 nylon suture. Five rats served as surgical controls (the CON group). These rats had the salivary glands exposed and the tympanic membrane punctured bilaterally. All rats were given 14 days to recover.

\section{Histology}

After the water control test, the rats in the CTX and DSAL groups were perfused with saline followed by $10 \% \mathrm{w} / \mathrm{v}$ buffered formalin. The CON group was tested in a second experiment, reported elsewhere (Spector, Guagliardo, \& St. John, 1996). At the completion of that experiment, the control rats were also perfused as described earlier. The tongue of each rat was removed and stored in formalin for several days, then soaked in distilled water for at least $30 \mathrm{~min}$, immersed in $0.5 \% \mathrm{wt} / \mathrm{vol}$ methylene blue, and rinsed briefly in distilled water. The epithelium was removed and pressed between two glass slides. Under a light microscope, taste pores appear as dark blue dots roughly centered in paler staining fungiform papillae. The percentage of fungiform papillae containing taste pores was quantified to determine whether the CT had regenerated during postsurgical testing.

\section{Data Analysis}

The primary dependent measure was the percentage of trials on which a correct response was made. Trials in which the rat did not press a lever (i.e., the limited hold expired) were discarded in deriving the percentage correct. A failure to discriminate the 2 salts would still result in reinforcement on approximately $50 \%$ of the trials.

An analysis of variance (ANOVA; Group $\times$ Time) was conducted on the mean overall percentage correct. The effect of $\mathrm{NaCl}$ or $\mathrm{KCl}$ concentration on the pre- and postsurgical percentage correct was examined for each group and each salt separately with 2-way repeated measures ANOVAs (Time $\times$ Concentration). If the
ANOVAs indicated significant differences, a test of simple effects was conducted with unpooled variance. In addition, the percentage correct was tested against $50 \%$ ( $t$ test) at all points to determine whether performance at a given concentration was significantly better than chance responding. The conventional $p=.05$ value was used to determine statistical significance.

\section{Results}

\section{Histology}

Rats in the CTX group averaged $4.7 \% \pm 1.0$ of fungiform papillae with a taste pore, as opposed to $96.0 \pm 0.9$ and $91.8 \pm 1.3$ in the CON and DSAL groups, respectively. An ANOVA indicated that the groups did not differ in the total number of fungiform papillae but did differ in the number of taste pores, $F(2,12)=165.7, p<.001$, and the percentage of fungiform papillae containing a taste pore, $F(2,12)=$ $2220.5, p<.001$. The CTX group differed from both the DSAL and CON groups on both measures $(p<.001)$. The latter groups did not differ on either measure.

\section{Salt Discrimination}

Transection of the CT and partial desalivation affected discrimination performance (Figure 2). For all groups, the average rate of correct responses during the presurgical test was $90 \%$. A Group $\times$ Time (before vs. after surgery) ANOVA revealed a main effect of Group, $F(2,12)=5.2$, $p<.025$, and Time, $F(1,12)=50.9, p<.001$, on the overall percentage correct, as well as a significant interaction, $F(2,12)=13.34, p<.001$. A test of simple effects indicated

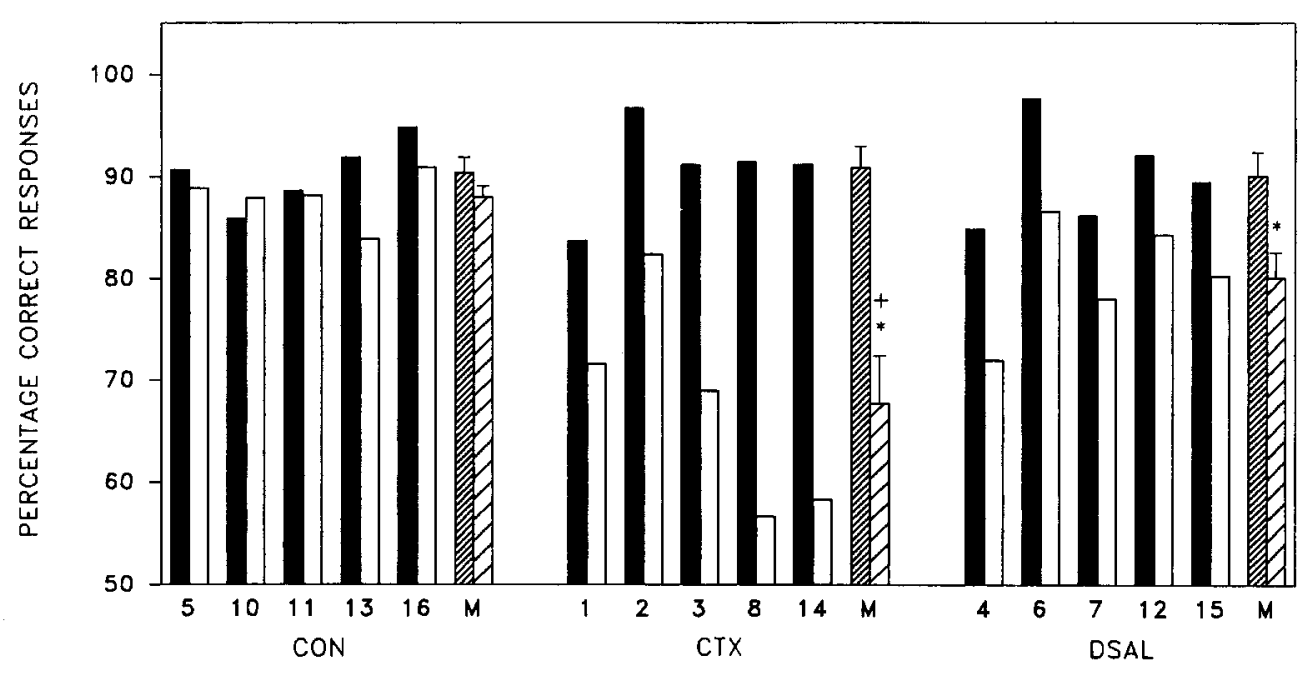

RAT NUMBER

Figure 2. Overall percentage correct for each rat with sham surgery (CON), partial desalivation (DSAL), and chorda tympani transection (CTX), both before (filled bars) and after (open bars) surgery. Group means $\pm S E$ are also given (before surgery = fine hatching; after surgery = coarse hatching). An ANOVA indicated a significant Group effect; plus (+) indicates significant difference in postsurgical percentage correct from both CON and DSAL, Tukey's honestly significant difference (HSD) test, $p<.05$. Asterisks indicate significant difference from the presurgical value within groups (Dependent $t$ test, $p<.05$ ). 
that the groups differed on the postsurgical percentage correct only, $F(2,12)=10.7, p<0.003$; the CTX group performed significantly more poorly than did the CON group $(p<.003)$ and the DSAL group $(p<.04)$. The DSAL and CON groups did not differ in postsurgical percentage correct. However, matched $t$ tests indicated that the postsurgical percentage correct was significantly lower than the presurgical percentage correct in both the CTX $(p<.01)$ and the DSAL $(p<.001)$ groups.

Discrimination performance (i.e., percentage correct) was differentially disrupted in the experimental groups as a function of both $\mathrm{NaCl}$ (Figure 3) and $\mathrm{KCl}$ (Figure 4) concentration. Separate Time $\times \mathrm{NaCl}$ Concentration ANOVAs conducted for each group revealed a significant main effect of Time in the DSAL, $F(1,4)=14.1, p<.02$, and CTX, $F(1,4)=20.0, p<.015$, groups. Post hoc matched $t$ tests revealed impaired performance at the 0.05 and $0.1 \mathrm{M}$ $\mathrm{NaCl}$ concentrations in the DSAL group and at all 3 concentrations in the CTX group (all $p$ values $<.05$ ). The rats clearly performed better as a function of increasing $\mathrm{NaCl}$ concentration: all groups, $F(2,8)>6.6, p<.02$. There was a significant Time $\times \mathrm{NaCl}$ Concentration interaction in the experimental groups but not in the CON group.

There was a significant main effect of both Time and $\mathrm{KCl}$ Concentration on the percentage correct in both the DSALTime: $F(1,4)=15.0, p<.02 ; \mathrm{KCl}$ Concentration: $F(2,8)=$ $10.4, p<.01$-and CTX-Time: $F(1,4)=16.1, p<.02$; $\mathrm{KCl}$ Concentration: $F(2,8)=5.3, p<.035$-groups but not in the CON group. The effect of Time was evident at all concentrations for both experimental groups (all $p$ values <.05), although the magnitude of these effects appeared greater in the CTX group than in the DSAL group
(Figure 4). There was no significant Time $\times \mathrm{KCl}$ Concentration interaction in any group.

In all cases, the overall percentage correct was significantly different from chance (i.e., from 50\%). In addition, the percentage correct for every concentration of $\mathrm{NaCl}$ and $\mathrm{KCl}$ significantly differed from $50 \%$ both before and after surgery in the DSAL and CON groups. In the CTX group, however, there was not statistical evidence to reject the hypothesis that the rats were responding to $0.05 \mathrm{M} \mathrm{NaCl}$ $(p>.2), 0.05 \mathrm{M} \mathrm{KCl}(p>.1)$, or $0.2 \mathrm{M} \mathrm{KCl}(p>.05)$ differently from chance.

\section{Water Control Test}

The overall percentage correct for the water test averaged $48.6 \pm 2.0(\mathrm{CON}), 49.8 \pm 2.0(\mathrm{CTX})$, and $48.3 \pm 3.0$ (DSAL), and none of the group means differed significantly from $50 \%$. In addition, no single rat had a percentage correct higher than 56.3 on the water control test, indicating the importance of a chemical cue in the discrimination (Figure 5). Further analysis indicated that although some rats tended to press exclusively on one lever or the other in the absence of a discriminable element in the sample stimuli, systematic position biases were not evident (Figure 6). It is interesting that there was an overall tendency to press the $\mathrm{KCl}$-appropriate lever when water was the stimulus. The rats averaged $64.4 \% \pm 5.7$ of their presses on the $\mathrm{KCl}$ lever, which was significantly greater than $50 \%, t(14)=2.51, p<.05$.

\section{Discussion}

The CT transection substantially impaired performance on the $\mathrm{NaCl}$-versus- $\mathrm{KCl}$ discrimination task. This result

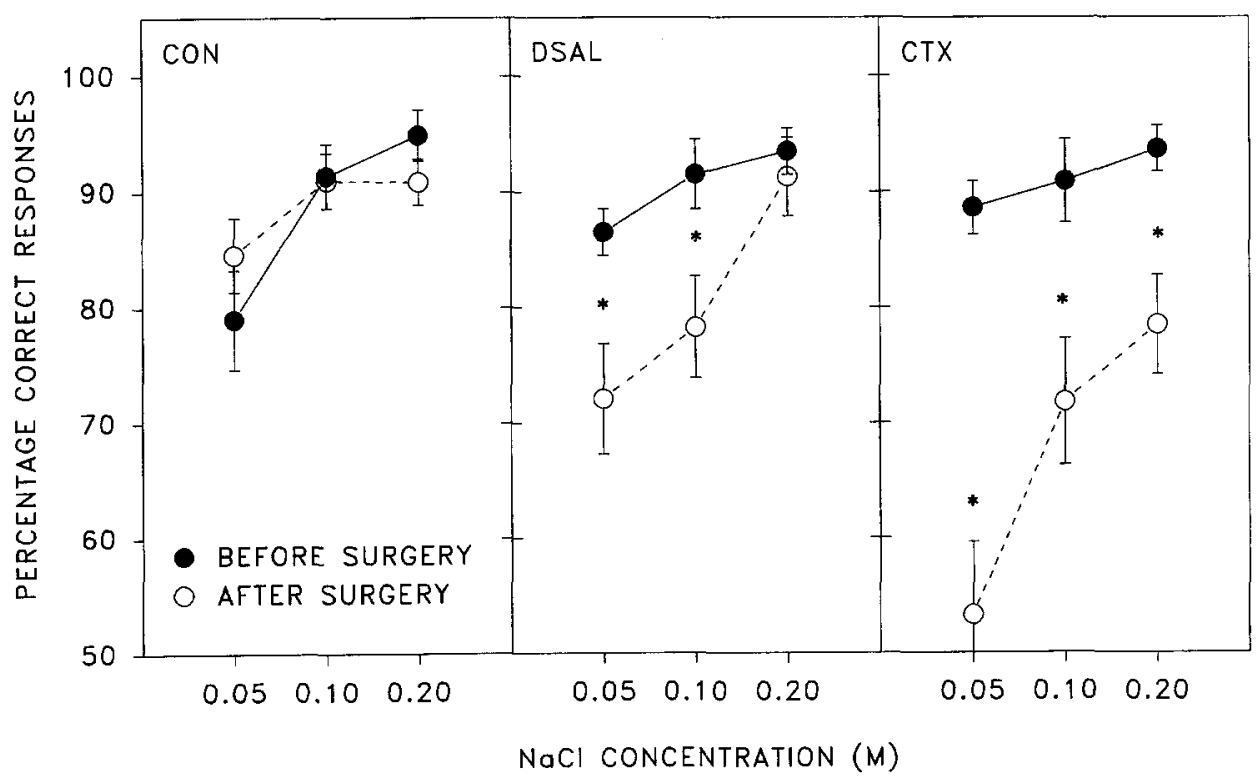

Figure 3. Percentage correct $\pm S E$ as a function of $\mathrm{NaCl}$ concentration before (filled circles) and after (open circles) sham surgery (CON), partial desalivation (DSAL), and chorda tympani transection (CTX). Asterisks indicate a significant difference from the presurgical percentage correct, matched $t$ test, $p<.05$. 


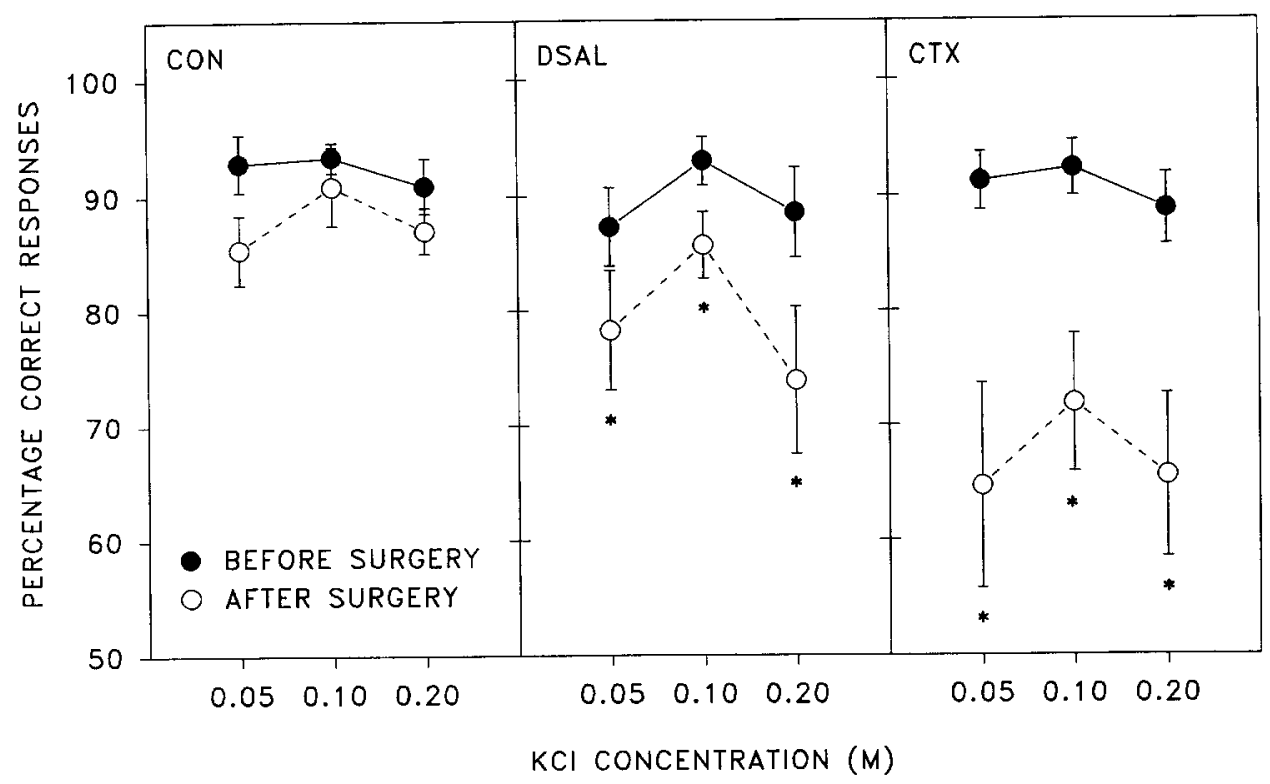

Figure 4. Percentage correct $\pm S E$ as a function of $\mathrm{KCl}$ concentration before (filled circles) and after (open circles) sham surgery (CON), partial desalivation (DSAL), and chorda tympani transection (CTX). Asterisks indicate a significant difference from the presurgical percentage correct, matched $t$ test, $p<.05$.

basically replicated previous work (Spector \& Grill, 1992; St. John et al., 1995) that had used a different experimental paradigm. In the present study, water-restricted rats received water reinforcement for pressing one lever if the sample stimulus was $\mathrm{NaCl}$ and a second lever if the sample stimulus was $\mathrm{KCl}$. In the earlier studies, rats were trained to suppress licking to one salt to avoid a mild footshock and to maintain licking to the other salt to avoid a 30-s time-out punishment (Spector \& Grill, 1992; St. John et al., 1995). Thus, considering the procedural differences in the 2 studies (e.g., the amount of stimulus sampled, type of response, and

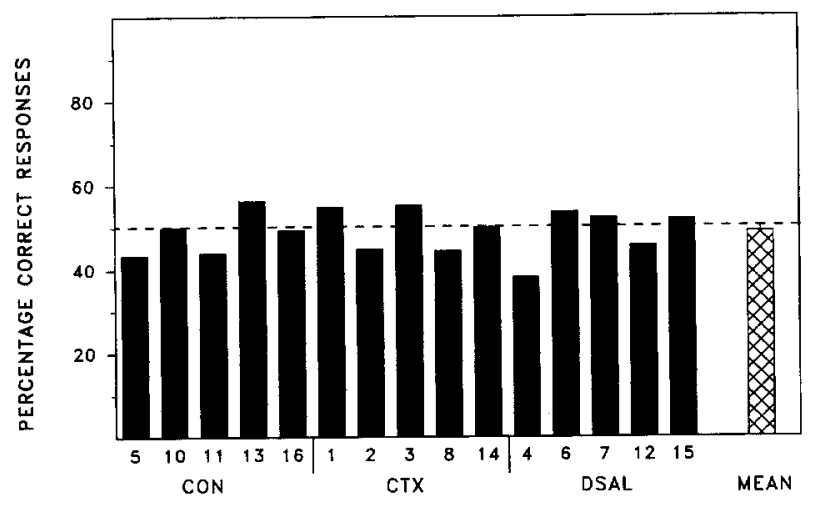

RAT NUMBER

Figure 5. Percentage correct for each subject during the water control test. Rats are arranged by group $(\mathrm{CON}=$ controls; DSAL = partial desalivation; $C T X=$ chorda tympani transection). The mean of all 15 rats $( \pm S E$ ) is also presented (hatched bar), and it did not significantly differ from $50 \%$. punishment contingencies), the results of these experiments agree rather well.

Some subtle differences between the studies are worthy of note. In the present study, although there was a clear and pronounced disruption in discrimination performance in the CTX group, the overall percentage correct was, nonetheless,

\section{WATER TEST}

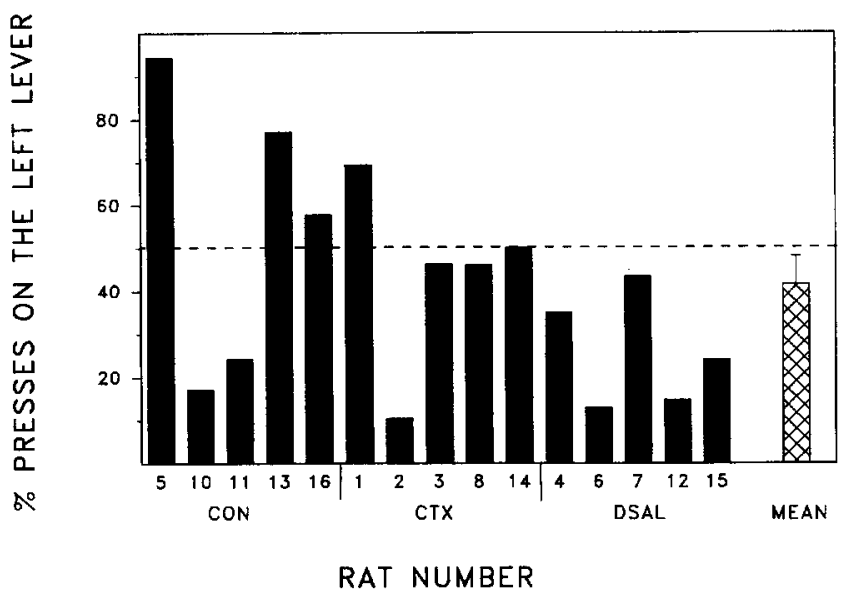

Figure 6. Percentage of presses on the left-hand lever (which may have been associated with either $\mathrm{NaCl}$ or $\mathrm{KCl}$ during training) for each subject during the water control test (i.e., when water was the sampled stimulus). Rats are arranged by group ( $\mathrm{CON}=$ controls; DSAL = partial desalivation; CTX = chorda tympani transection). The mean of all 15 rats $( \pm S E)$ is also presented (hatched bar), and it did not significantly differ from $50 \%$. Note that there is no consistent bias to press (or not press) the left-hand lever. 
significantly better than chance $(66.7 \% \pm 4.7)$. This study makes it clear that most of this residual discriminability occurred because rats in the CTX group were able to respond relatively well to 0.1 and $0.2 \mathrm{M} \mathrm{NaCl}$, as well as to $0.1 \mathrm{M}$ $\mathrm{KCl}$. Although there were signs in the previous shockavoidance data that some residual discriminability survived CT transection, this conclusion was not unequivocal (Spector \& Grill, 1992; St. John et al., 1995). The shockavoidance procedure provided reliable data about the gross effects of neural manipulations on taste discrimination; certain features of that paradigm, however, may have limited interpretation of more modest effects. For example, when $\mathrm{NaCl}$ and $\mathrm{KCl}$ presumably became more difficult to discriminate, there was a bias toward suppressing licking to both salts (i.e., the rats responded as if they preferred the time-out punishment to the shock). Thus the response was no longer simply a measure of stimulus control (i.e., how much the stimulus resembled the presurgically trained stimulus) but was influenced by motivational factors (i.e., the bias to avoid shock). In the present 2-lever discrimination procedure, the contingencies for correct and incorrect responses were identical regardless of which salt was sampled, so there was no inherent bias toward one lever or the other. This is supported by the finding that there was no consistent lever bias across rats during the water test (Figure 6). In addition, in the earlier studies (Spector \& Grill, 1992; St. John et al., 1995), postsurgical performance might have been diminished by motivational factors (such as the bias to avoid shock) that inhibited reacquisition of the discrimination after the CT transection. In other words, the bias to avoid shock could have limited appropriate responding to 1 of the 2 salts (i.e., licking throughout a 5-s trial). In the 2-lever discrimination paradigm, because the contingencies arranged for pressing one lever versus the other were the same, there was no inherent obstacle to relearning the task following surgery. Despite the procedural differences, however, both procedures clearly demonstrated that CT transection impairs performance on a presurgically learned operant discrimination of $\mathrm{NaCl}$ and $\mathrm{KCl}$.

There was some evidence of a bias toward the $\mathrm{KCl}$ appropriate lever during the water test. This result does not undermine the logic of the preceding discussion, provided the bias was not a result of motivational variables such as the punishment contingencies. Indeed, one possibility is that the response on the $\mathrm{KCl}$ lever reflects a perceived similarity between $\mathrm{KCl}$ and distilled water. If so, this result could mean that $\mathrm{KCl}$ is perceived as weaker (i.e., more like water) than $\mathrm{NaCl}$ at isomolar concentrations.

Although, in general, the results of the two studies on $\mathrm{NaCl}$ vs. KCl discriminability are comparable, these results differ from those of a recent taste aversion generalization study (St. John, Markison, \& Spector, in press). In that study, rats with $\mathrm{CT}$ transection that had formed a robust conditioned taste aversion to $0.1 \mathrm{M} \mathrm{NaCl}$ were tested in a gustometer for generalization of the aversion to other $\mathrm{NaCl}$ concentrations and $\mathrm{KCl}(0.03,0.1$, and $0.3 \mathrm{M})$. Because the results of the present study indicate that $\mathrm{CT}$ transection impairs the discriminability of these two stimuli, it was expected that aversions to $\mathrm{NaCl}$ might at least partially generalize to $\mathrm{KCl}$ in CT-transected rats. No evidence for a generalization was observed, however. As previously indicated, rats in the current experiment retained some partial competence in the task after CT transection. It is possible that performance in the operant discrimination tasks (Spector \& Grill, 1992, St. John et al., 1995, the current study) is impaired whenever the neural signals evoked by $\mathrm{NaCl}$ and $\mathrm{KCl}$ become somewhat more similar, whereas taste-aversion generalization is manifested only if the neural signals evoked by the 2 salts become nearly identical. That is, the generalization gradient is steeper under taste-aversion procedures. Indeed, when amiloride application preceded tasteaversion conditioning to $0.5 \mathrm{M} \mathrm{NaCl}$, the aversion generalized to nonsodium salts (Hill, Formaker, \& White, 1990). A second procedural difference between the taste-aversion study and the current one was that CT transection preceded the conditioning of the $\mathrm{NaCl}$ aversion, whereas in the current study rats were tested both before and after surgery. The differences in the results of the two types of paradigms will be important to reconcile in future experiments, because such findings have implications concerning the role of the $\mathrm{CT}$ in the gustatory processing of salt stimuli.

Transection of the CT in the middle ear denervates taste buds on the anterior tongue and partially removes the parasympathetic innervation of the sublingual and submaxillary salivary glands (Hellekant \& Kasahara, 1973; Young \& Van Lennep, 1978). Therefore, the effects just described could result from an alteration in taste input or from a disruption of the salivary environment of the oral cavity. Discrimination performance was impaired after extirpation of these glands. In the present study, however, several lines of evidence indicate that the magnitude of the deficits in the DSAL group were not as severe as in the CTX group. First, the DSAL group performed as well to $0.2 \mathrm{M} \mathrm{NaCl}$ after surgery as before, whereas the CTX group showed a significant reduction in performance to that concentration. Second, the mean overall percentage correct during the postsurgical test did not statistically differ between the CON group and the DSAL group. In contrast, the overall percentage correct in the CTX group was significantly lower than that in both the CON and DSAL groups. Third, the percentage correct at $0.05 \mathrm{M} \mathrm{NaCl}, 0.05 \mathrm{M} \mathrm{KCl}$, or $0.2 \mathrm{M}$ $\mathrm{KCl}$ was not statistically different from $50 \%$ in the CTX group; thus, there was not sufficient evidence to reject the null hypothesis that the CTX group was responding to these stimuli at chance levels. Although the DSAL group performed significantly more poorly at most concentrations after surgery, in every case the performance was significantly better than chance. Extirpation of the sublingual and submaxillary salivary glands presumably disrupts salivary function more severely than CT transection, yet the behavioral effects of the former manipulation were less severe than those of the latter. Thus, it seems unlikely that the effects of CT transection can be explained solely by a disruption of the salivary environment, and the present results strongly implicate the denervation of anterior tongue taste buds as the predominant mechanism for the reduction of salt discriminability.

Nevertheless, extirpation of the sublingual and submaxil- 
lary glands did affect salt discriminability, except at the highest tested $\mathrm{NaCl}$ concentration $(0.2 \mathrm{M})$. Other studies of $\mathrm{NaCl}$ and $\mathrm{KCl}$ preference, unconditioned licking of $\mathrm{NaCl}$ in brief access taste trials, and licking to $\mathrm{NaCl}$ and $\mathrm{KCl}$ in sodium-depleted rats also indicate that some deficits in salt taste perception may follow extirpation of these salivary glands (Brosvic \& Hoey, 1990; Catalanotto \& Sweeney, 1973; Cauthon et al., 1994; Markison et al., 1995; Thrasher \& Fregly, 1980). It is difficult to speculate on the mechanism, although there are at least two possibilities. First, saliva contains both sodium and potassium ions. Thus, removal of these glands presumably alters the adaptation state of the taste receptors (see Thrasher \& Fregly, 1980). Second, saliva may contain a host of growth factors that could play a role in the functional integrity of taste-receptor cells (e.g., Cano \& Rodriguez-Echandia, 1980; Gresik, Van der Noen, \& Barka, 1979). Previous studies have shown a relationship between salt discriminability and the number of taste buds on the anterior tongue (St. John et al., 1995). Our histological results, however, indicate that a reduction in taste bud number does not appear to be the cause of the effects in the DSAL group described here. This finding does not preclude the possibility that the removal of the salivary glands affected the number of cells per taste bud, constituents of the taste bud (e.g., number of amiloride-sensitive sodium channels), or efficiency of transduction processes. It is unlikely that the effects of desalivation were simply caused by an inability to rinse the tongue, however. When the data were reanalyzed to include only trials that followed a reinforced trial (i.e., trials that were preceded by a 40 -lick water rinse), the results virtually matched the results presented here.

Brosvic and Hoey (1990) did not find any effect of partial desalivation on the discrimination of $0.068 \mathrm{M} \mathrm{NaCl}$ and $\mathrm{KCl}$, a result not entirely consistent with the moderate reduction in discriminability found in the current study. Although a variety of procedural issues could be raised to address the differential results, perhaps the most critical is that this study used a range of concentrations of both stimuli $(0.05-0.2 \mathrm{M})$, whereas Brosvic and Hoey used only one concentration of each taste stimulus. Concentration was varied in the current study in an effort to render intensity an irrelevant cue. If the $\mathrm{KCl}$ and $\mathrm{NaCl}$ concentrations used in the current study overlapped in intensity, then intensity could not govern appropriate responding. Therefore, the differential effects seen in the two studies may be due to the fact that in the Brosvic and Hoey study a combination of intensity and quality cues might have controlled responding, whereas in the present study, quality was the primary factor. In any event, the differences in the results are relatively minor given that the partially desalivated rats in the present study still responded correctly $80 \%$ of the time.

Therefore, it appears that deficits in salt discriminability following CT transection are caused, at least in part, by an alteration in gustatory input, even though such manipulation spares about $85 \%$ of the total complement of rat taste buds (Miller, 1977). Electrophysiological studies have strongly implicated a role for the CT in the neural coding of salt taste. For example, in rats and hamsters, the CT contains a large population of amiloride-sensitive fibers that respond to $\mathrm{NaCl}$ but not $\mathrm{KCl}$ at the midrange concentrations used in the present study (DeSimone \& Ferrell, 1985; Hettinger \& Frank, 1990; Ninomiya \& Funakoshi, 1988). These fibers have been strongly implicated in providing a neural signal that distinguishes $\mathrm{NaCl}$ from nonsodium salts. Hill, Formaker, and White (1990) found that a taste aversion conditioned to $0.5 \mathrm{M} \mathrm{NaCl}$ uncharacteristically generalized to $\mathrm{KCl}$ when the conditioned stimulus was delivered following an amiloride pretreatment. Because CT transection removes at least some of the amiloride-suppressible fibers, the neurotomy may alter the perceived taste quality of $\mathrm{NaCl}$. In addition, CT transection elevates the detection threshold for $\mathrm{NaCl}$ by about 1-2 orders of magnitude (Slotnick et al., 1991; Spector et al., 1990). Although all concentrations of $\mathrm{NaCl}$ used in the present study were above the behaviorally derived detection threshold after CT transection (Slotnick et al., 1991; Spector et al., 1990), performance to concentrations near $0.05 \mathrm{M}$ was less than maximal in the detectionthreshold studies. Furthermore, O'Keefe, Schumm, and Smith (1994) found that CT transection attenuated lick rate to 0.03 and $0.06 \mathrm{M} \mathrm{NaCl}$ in sodium-deprived rats, whereas responding to higher concentrations was unaffected. Thus, some $\mathrm{NaCl}$ concentrations may have been made weaker by CT transection in the current study. Finally, there is evidence that $\mathrm{CT}$ transection reduces the perceived intensity of $\mathrm{KCl}$. St. John, Markison, and Spector (in press) recently demonstrated that CT transection substantially weakened conditioned taste aversions when $0.1 \mathrm{M} \mathrm{KCl}$ was the conditioned stimulus. Taking into account the available behavioral evidence, then, it is reasonable to infer that CT transection affects the perceived intensity of the 2 salts and may affect the perceived quality as well. The 2 salts may even remain somewhat discriminable at high concentrations after the neurotomy, but the postsurgical decrease in perceived intensity and hypothesized alterations in taste quality may make appropriate responding more difficult.

Finally, as previously noted, rats in the CTX group did respond at better-than-chance levels overall; the percentages correct to $0.1 \mathrm{M} \mathrm{NaCl}, 0.2 \mathrm{M} \mathrm{NaCl}$, and $0.1 \mathrm{M} \mathrm{KCl}$ were significantly better than $50 \%$. This implicates a role for the remaining gustatory nerves in salt discrimination. The glossopharyngeal nerve innervates the majority of rat taste buds (Miller, 1977). Spector and Grill (1992), however, found no effect of glossopharyngeal nerve transection on a $\mathrm{NaCl}$-versus- $\mathrm{KCl}$ discrimination as assessed in a conditioned shock-avoidance procedure. It is interesting to note that the glossopharyngeal nerve does not appear to contain electrophysiologically defined sodium-specific fibers that differentiate sodium and nonsodium salts, as the CT does (Boudreau, Do, Sivakumar, Oravec, \& Rodriguez, 1987; Boudreau, Hoang, Oravec, \& Do, 1983; Frank, 1991; Frank, Contreras, \& Hettinger, 1983). Sodium-specific fibers have not been identified in the superior laryngeal nerve of hamsters (Smith \& Hanamori, 1991). The greater superficial petrosal nerve responds to $\mathrm{NaCl}$ (Nejad, 1986), but neither a single fiber analysis nor a test of the effects of amiloride on the response to $\mathrm{NaCl}$ of this nerve has been published. Given the results of glossopharyngeal nerve transection studies and 
the electrophysiological profile of the gustatory nerves, the greater superficial petrosal nerve may provide the remaining discriminable signal for sodium and nonsodium salts. This hypothesis remains to be tested.

\section{References}

Boudreau, J. C., Do, L. T., Sivakumar, L., Oravec, J., \& Rodriguez, C. A. (1987). Taste systems of the petrosal ganglion. Chemical Senses, 12, 437-458.

Boudreau, J. C., Hoang, N. K., Oravec, J., \& Do, L. T. (1983). Rat neurophysiological taste responses to salt solutions. Chemical Senses, 8, 131-150.

Breslin, P. A. S., Spector, A. C., \& Grill, H. J. (1993). Chorda tympani section decreases the cation specificity of depletioninduced sodium appetite in rats. American Journal of Physiology, 264, R319-R323.

Breslin, P. A. S., Spector, A. C., \& Grill, H. J. (1995). Sodium specificity of salt appetite in Fischer 344 and Wistar rats is impaired by chorda tympani nerve transection. American Journal of Physiology, 269, R350-R356.

Brosvic, G. M., \& Hoey, N. E. (1990). Taste detection and discrimination performance of rats following selective desalivation. Physiology \& Behavior, 48, 617-623.

Cano, J., \& Rodriguez-Echandia, E. L. (1980). Degenerating taste buds in sialectomized rats. Acta Anamatomica, 106, 487-492.

Catalanotto, F. A., \& Sweeney, E. A. (1973). Long-term effects of selective desalivation on taste acuity in rats. Archives of Oral Biology, 18, 941-952.

Cauthon, R., Garcea, M., \& Spector, A. C. (1994). Taste-guided unconditioned licking to suprathreshold sodium chloride concentrations is unaffected by selective lingual denervation [abstract]. Chemical Senses, 19, 452.

DeSimone, J. A., \& Ferrell, F. (1985). Analysis of amiloride inhibition of chorda tympani taste response of rat to $\mathrm{NaCl}$. American Journal of Physiology, 249, R52-R61.

Frank, M. E. (1991). Taste-responsive neurons of the glossopharyngeal nerve of the rat. Journal of Neurophysiology, 65, 14521463.

Frank, M. E., Contreras, R. J., \& Hettinger, T. P. (1983). Nerve fibers sensitive to ionic taste stimuli in the chorda tympani of the rat. Journal of Neurophysiology, 50, 941-960.

Gresik, E. W., Van der Noen, H., \& Barka, T. (1979). Epidermal growth factor-like material in rat submandibular gland. American Journal of Anatomy, 156, 83-89.

Hellekant, G., \& Kasahara, K. (1973). Secretory fibers in the trigeminal part of the lingual nerve to the mandibular salivary gland of the rat. Acta Physiologica Scandanavica, 89, 198-207.

Hettinger, T. P., \& Frank, M. E. (1990). Specificity of amiloride inhibition of hamster taste responses. Brain Research, 513, 24-34.

Hill, D. L., Formaker, B. K., \& White, K. S. (1990). Perceptual characteristics of the amiloride-suppressed sodium chloride taste response in the rat. Behavioral Neuroscience, 104, 734-741.

Markison, S., St. John, S. J., \& Spector, A. C. (1995). Glossopharyngeal nerve transection does not compromise the specificity of taste-guided sodium appetite in rats. American Journal of Physiology, 269, R215-R221.

Miller, I. J. (1977). Gustatory receptors of the palate. In Y. Katsuki, M. Sato, S. Takagi, \& Y. Oomura (Eds.), Food intake and chemical senses (pp. 173-186). Tokyo: University of Tokyo Press.

Morrison, G. R. (1967). Behavioural response patterns to salt stimuli in the rat. Canadian Journal of Psychology, 21, 141-152.

Nejad, M. S. (1986). The neural activities of the greater superficial petrosal nerve of the rat in response to chemical stimulation of the palate. Chemical Senses, 11, 283-293.

Ninomiya, Y., \& Funakoshi, M. (1988). Amiloride inhibition of responses of rat single chorda tympani fibers to chemical and electrical tongue stimulations. Brain Research, 451, 319-325.

O'Keefe, G. B., Schumm, J., \& Smith, J. C. (1994). Loss of sensitivity to low concentrations of $\mathrm{NaCl}$ following bilateral chorda tympani nerve sections in rats. Chemical Senses, 19, 169-184.

Slotnick, B. M., Sheelar, S., \& Rentmeister-Bryant, H. (1991). Transection of the chorda tympani and insertion of ear pins for stereotaxic surgery: Equivalent effects on taste sensitivity. Physiology \& Behavior, 50, 1123-1127.

Smith, D. V., \& Hanamori, T. (1991). Organization of gustatory sensitivities in hamster superior laryngeal nerve fibers. Journal of Neurophysiology, 65, 1098-1113.

Sollars, S. I., \& Bernstein, I. L. (1992). Sodium appetite after transection of the chorda tympani nerve in Wistar and Fischer 344 rats. Behavioral Neuroscience, 106, 1023-1027.

Sollars, S. I., \& Bernstein, I. L. (1994). Gustatory deafferentation and desalivation: Effects on $\mathrm{NaCl}$ preference of Fischer 344 rats. American Journal of Physiology, 266, R510-R517.

Sollars, S. I., Sollars, P. J., \& Bernstein, I. L. (1991). Reversal of the sodium chloride aversion of Fischer 344 rats by chorda tympani nerve transection. Behavioral Neuroscience, 105, 603-605.

Spector, A. C., Andrews-Labenski, J., \& Letterio, F. C. (1990). A new gustometer for psychophysical taste testing in the rat. Physiology \& Behavior, 47, 795-803.

Spector, A. C., \& Grill, H. J. (1992). Salt taste discrimination after bilateral section of the chorda tympani or glossopharyngeal nerves. American Journal of Physiology, 263, R169-R176.

Spector, A. C., \& Grill, H. J. (1994). Behavioral evidence for the primacy of the chorda tympani nerve in sodium chloride taste. In K. Kurihara, N. Suzuki, \& H. Ogawa (Eds.), Olfaction \& Taste (Vol. 11, pp. 249-252). Tokyo: Springer-Verlag.

Spector, A. C., Guagliardo, N. A., \& St. John, S. J. (1996). Amiloride disrupts $\mathrm{NaCl}$ versus $\mathrm{KCl}$ discrimination performance: Implications for salt taste coding in the rat. Journal of Neuroscience, 16, 8115-8122.

Spector, A. C., Redman, R., \& Garcea, M. (1996). The consequences of gustatory nerve transection on taste-guided licking of sucrose and maltose in the rat. Behavioral Neuroscience, 110 , 1096-1109.

Spector, A. C., Schwartz, G. J., \& Grill, H. J. (1990). Chemospecific deficits in taste detection after selective gustatory deafferentation in rats. American Journal of Physiology, 258, R820-R826.

St. John, S. J., Garcea, M., \& Spector, A. C. (1994). Combined but not single gustatory nerve transection substantially alters tasteguided licking behavior to quinine in rats. Behavioral Neuroscience, 108, 131-140.

St. John, S. J., Markison, S., Guagliardo, N. A., Hackenberg, T. D., \& Spector, A. C. (1996). Chorda tympani transection and partial desalivation differentially disrupt two-lever salt discrimination performance in rats [abstract]. Chemical Senses, 21, 675.

St. John, S. J., Markison, S., \& Spector, A. C. (1995). Salt discriminability is related to number of regenerated taste buds after chorda tympani nerve transection in rats. American Journal of Physiology, 269, R141-R153.

St. John, S. J., Markison, S., \& Spector, A. C. (in press). Chorda tympani transection disrupts taste aversion learning to $\mathrm{KCl}$, but not $\mathrm{NaCl}$. Behavioral Neuroscience.

Thrasher, T. N., \& Fregly, M. J. (1980). Factors affecting salivary sodium concentration, $\mathrm{NaCl}$ intake, and preference threshold and their interrelationships. In M. R. Kare, M. J. Fregly, \& R. A. Bernard (Eds.), Biological and behavioral aspects of salt intake (pp. 145-165). New York: Academic Press. 
Wong, R., \& Kraintz, L. (1977). Interlick interval distribution of desalivated and control rats. Behavioral Biology, 21, 141-145.

Yamamoto, T., Shimura, T., Sako, N., Yasoshima, Y., \& Sakai, N. (1994). Some critical factors involved in formation of conditioned taste aversion to sodium chloride in rats. Chemical Senses, 19, 209-217.
Young, J. A., \& Van Lennep, E. W. (1978). The morphology of the salivary glands. San Diego, CA: Academic Press.

Received June 11, 1996

Revision received August 19, 1996

Accepted September 16, 1996 .

\section{American Psychological Association SUBSCRIPTION ClaIMS INFORMATION}

Today's Date:

We provide this form to assist members, institutions, and nonmember individuals with any subscription problems. With the appropriate information we can begin a resolution. If you use the services of an agent, please doNOT duplicate claims through them and directly to us. PLEASE PRINT CLEARLY AND IN INK IF POSSIBLE.

PRINT FULL NAME OR KEY NAME OF INSTTTUTION

ADDRESS

\begin{tabular}{lll}
\hline & & \\
\hline CITY & STATE/COUNTRY & ZIP
\end{tabular}

YOUR NAME AND PHONE NUMBER

TITLE
MEMBER OR CUSTOMER NUMBER (MAY BEFOUNDON ANY PASTISSUELABEL)

DATE YOUR ORDER WAS MAIIED (OR PHONED)

_PREPAID —CHECK $\_$CHECK/CARD CLEARED DATE:

(If possible, send a copy, front and back, of your cancelled check to help us in our research of your claim.)

VOLUME OR YEAR MISSING DAMAGED

$$
\text { ISSUES: }
$$

NUMBER OR MONTH

Thank you. Once a claim is received and resolved, delivery of replacement issues routinely takes 4-6 weeks.

DATE RECEIVED:

ACTION TAKEN:

STAFF NAME:
DATE OF ACTION:

INV. NO. \& DATE

LABEL NO. \& DATE:

Send this form to APA Subscription Claims, 750 First Street, NE, Washington, DC 20002-4242

PLEASE DO NOT REMOVE. A PHOTOCOPY MAY BE USED. 